Original Article

\title{
VARIATIONS IN DORSALIS PEDIS ARTERY
}

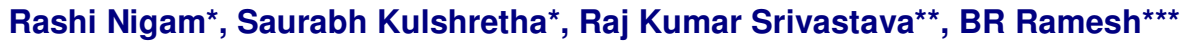 \\ *Department of Anatomy, Rama Medical College, Hospital \& Research Centre, Kanpur, UP, India \\ ${ }^{\star \star}$ Department of Anatomy, Hind Institute of Medical Sciences, Lucknow, UP, India \\ ${ }^{* * *}$ Department of Anatomy, Dr. B.R. Ambedkar Medical College, Bengaluru, Karnataka, India
}

\begin{abstract}
Introduction: Dorsalis pedis artery is the chief artery of the dorsum of foot and is the artery of choice for grafting in vascular surgery of ischemic lower limbs in diabetic patients.
\end{abstract}

Material \& Methods: Dorsalis pedis artery was dissected and traced during routine cadaveric dissection in 41 foots.

Observation \& Results: We observed origin of dorsalis pedis artery from peroneal artery in $2.44 \%$ cases. Five branches from dorsalis pedis artery were observed in $2.44 \%$ and 6 branches in $2.44 \%$ cases.

Conclusion: Study of variation in origin and branching pattern of dorsalis pedis artery is helpful in delimiting the graft.

Keywords: Dorsalis pedis artery, dissection, variations, origin, branches.

\section{INTRODUCTION}

The arterial pattern of the human body is one of the systems that show a large number of variations. A variation in the course and branching pattern of an artery is both interesting and significant for both clinicians and anatomists [1]. The chief artery of the dorsum of the foot is the dorsalis pedis artery [2]. The term "Dorsalis pedis artery" is obtained from the Latin. The word dorsalis means on the dorsal side. The word pedis means the foot. So, this is the artery which supplies the dorsal side of the foot [3]. The other names of this artery are arteria dorsalis pedis and dorsal artery of foot [4].

In the effort of salvaging the ischemic limb in case of diabetic neuropathy, dorsalis pedis artery bypass plays a major role [5]. The branches of dorsalis pedis artery are used in distal bypass [6]. In revascularization of the foot, dorsalis pedis artery is used as an outflow vessel [7]. It is the most preferred recipient vessel for bypass graft. Variations in course and branches pose a dangerous situation during vascular surgeries. Only few studies are available on the branching pattern of the dorsalis pedis artery and more so in Karnataka. So present study has been done in forty one foot during routine dissection in the department of Anatomy, Dr. B. R. Ambedkar Medical College, K.G. Halli, Bengaluru.

\section{MATERIAL AND METHODS}

The dorsalis pedis artery was dissected and traced from its origin up to first metatarsal space, the number of branches and the branching pattern of dorsalis pedis artery was noted.

\section{OBSERVATIONS AND RESULTS}

In 40 cases, dorsalis pedis artery was arising from

Address for Correspondence:

Dr. Rashi Nigam, Department of Anatomy, Rama Medical College, Hospital \& Research Centre, Mandhana, Kanpur-209217, UP, India. | Email-drrashinigam@gmail.com 
anterior tibial artery which is normal, while in one case $(2.44 \%)$ it was arising from peroneal artery. Five branches from dorsalis pedis artery was observed in $2.44 \%$ and 6 branches in $2.44 \%$ cases (Table 1 ). In $7.39 \%$ cases, dorsalis pedis artery has a short course and divided into medial and lateral branches named as dorsalis arteria medialis and dorsalis arteria lateralis respectively. The medial branch continued as the first dorsal metatarsal artery and joined the plantar arch. The lateral branch gave off the second, third and fourth metatarsal arteries. Absence of the arcuate artery was also seen in $2.44 \%$ of cases. Tetrafurcation of anterior tibial artery (i.e. lateral malleolar artery, medial malleolar artery, lateral tarsal artery and dorsalis pedis artery arises at the same point over the ankle joint) was present in $2.44 \%$ of cases. Lateral malleolar artery was a branch of dorsalis pedis artery in $2.44 \%$ of cases. (Fig. 1 ).

Table 1: Origin and branching pattern of dorsalis pedis artery

\begin{tabular}{|l|c|c|}
\hline $\begin{array}{l}\text { Origin of dorsalis pedis } \\
\text { artery }\end{array}$ & $\begin{array}{c}\text { Numbers } \\
\text { of cases }\end{array}$ & Percentage \\
\hline $\begin{array}{l}\text { From anterior tibial artery } \\
\text { (normal) }\end{array}$ & 40 & $97.56 \%$ \\
\hline From peroneal artery & 1 & $2.44 \%$ \\
\hline \multicolumn{3}{|l|}{ Branches of dorsalis pedis artery } \\
\hline $\begin{array}{l}4 \text { branches (normal } \\
\text { pattern) }\end{array}$ & 39 & $95.12 \%$ \\
\hline 6 branches & 1 & $2.44 \%$ \\
\hline 5 branches & 1 & $2.44 \%$ \\
\hline
\end{tabular}

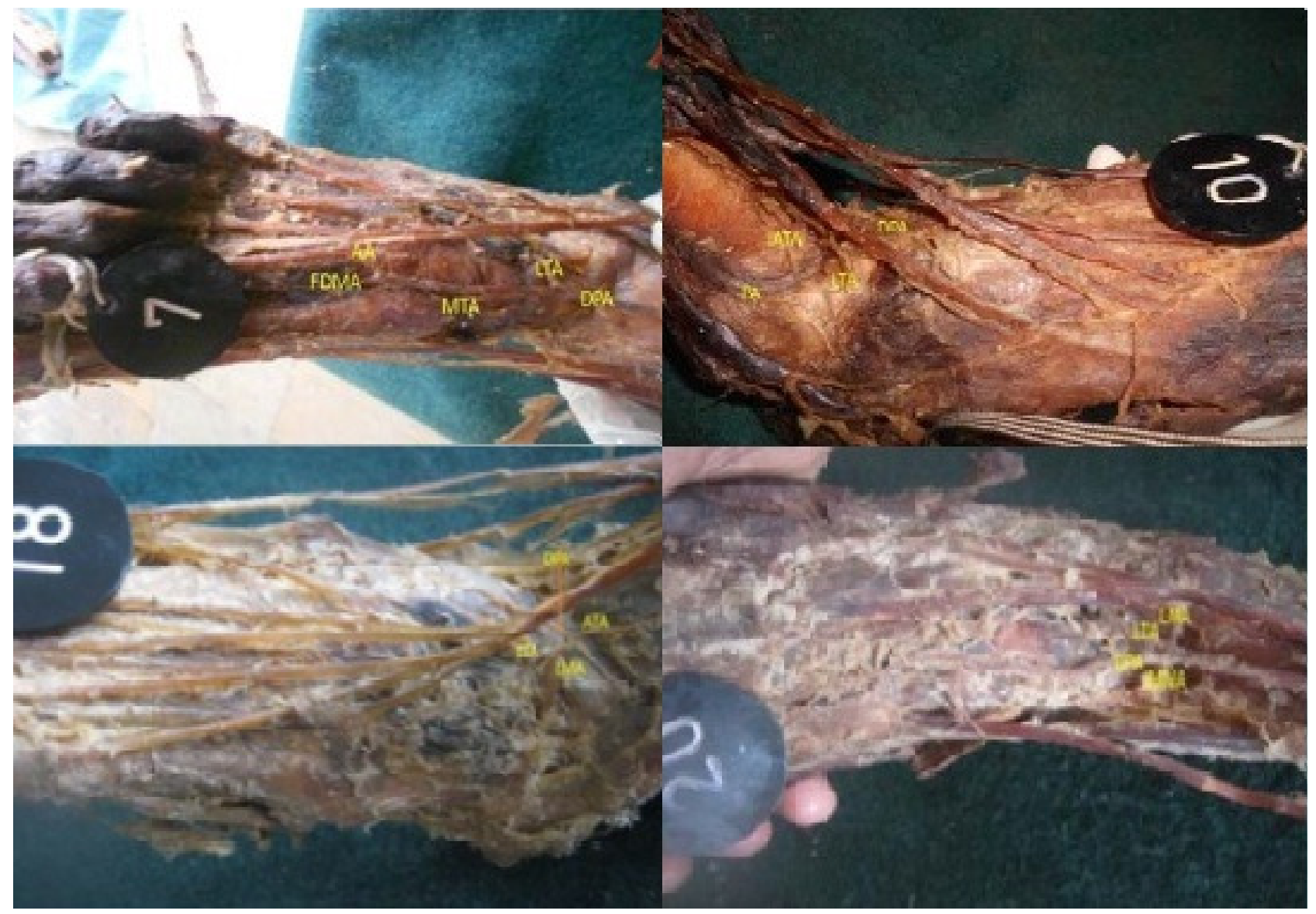

Fig. 1: Variations in origin and branching pattern of dorsalis pedis artery. (DPA: Dorsalis pedis artery, FDMA: First dorsal metatarsal artery, LMA: Lateral malleolar artery, LTA: Lateral tarsal artery, MMA: Medial malleolar artery, MTA: Medial tarsal artery, PA: Peroneal artery) 


\section{DISCUSSION}

In present study, origin of dorsalis pedis artery from peroneal artery was present in $2.44 \%$ of cases while Vijyalakshmi et al. (2011) have noted in $8 \%$ of cases [2]. Vaishnani et al. (2012) and Surekha et al. (2013) also reported origin of dorsalis pedis artery from peroneal artery $[8,9]$. We noted that in $7.39 \%$ cases, dorsalis pedis artery has a short course and divided into medial and lateral branches named as dorsalis arteria medialis and dorsalis arteria lateralis respectively. The medial branch continued as the first dorsal metatarsal artery and joined the plantar arch. The lateral branch gave off the second, third and fourth metatarsal arteries cases while Vijyalakshmi et al. (2011) noted this pattern in $16 \%$ cases [2].

Mitra et al. (2007) reported a case of bilateral absence of the arcuate artery in a 60 years old male [10] while we have noted absence of the arcuate artery in $2.44 \%$ of cases. Vijyalakshmi et al. (2011) and Rajeshwari et al. (2013) also noted absence of the arcuate artery in $6 \%$ and $16.67 \%$ cases respectively $[2,11]$. In the present study, tetrafurcation of anterior tibial artery (i.e. lateral malleolar artery, medial malleolar artery, lateral tarsal artery and dorsalis pedis artery arises at the same point over the ankle joint) was present in $2.44 \%$ of cases. Also in our study, lateral malleolar artery was a branch of dorsalis pedis artery in $2.44 \%$ of cases. These above two branching pattern of the dorsalis pedis artery has not been described in the literature.

\section{CONCLUSION}

Pulsation of dorsalis pedis artery regarding its location has been reported to vary. The skin of the dorsum of foot has been used for both proximal and distal skin grafting since the dorsalis pedis artery gives off number of cutaneous branches which maintains the nutrition of the graft. Hence the study of variation in origin and branching pattern of dorsalis pedis artery is helpful in delimiting the graft. The individual branches of the dorsalis pedis artery may be used for injecting chemotherapeutic agent for malignancies which are in the initial stages. Dorsalis pedis artery is very useful for vascular surgery in case of ischemia of lower limb.

\section{REFERENCES}

1. Bergman RA, Afifi AK. Miyauchi R. Compendium of human anatomic variation, text atlas and World literature. Baltimore: Urban and Schwarzenberg. 1988; 64-66.

2. Vijayalakshmi S, Raghunath G, Shenoy V. Anatomical study of dorsalis pedis artery and its clinical correlations. Journal of Clinical and Diagnostic Research. 2011; 5(2):287-290.

3. Last R.J. Anatomy Regional and Applied. $6^{\text {th }}$ ed. Singapore: Churchill livingstone. 1978. p. 680

4. http:File:///H:/medical dictionary.php.htm.

5. Albeir Y Mousa, Robert S Dieter, Arvinda Nanjundappa. Anatomy of the pedal arch and implications for tibiopedal access. Supplement to endovascular today. 2012; 3-5.

6. Krag $\mathrm{C}$ and Riegels- Nielsen $\mathrm{P}$. The dorsalis pedis flap for lower leg reconstruction. Acta Orthop Scand. 1982; 53(3): 487493.

7. Pomposelli FB, Marcaccio EJ, Gibbons GW, Campbell DR, Freeman DV, Burgess AM, Miller A, LoGerfo FW. Dorsalis pedis arterial bypass: Durable limb salvage for foot ischemia in patients with diabetes mellitus: J Vasc Surg. 1995; 21(3):375384.

8. Vaishnani H, Gujar S, Gadekar S, Bondre KV, Shah GV. An abnormal unilateral origin of dorsalis pedis artery- a case report. Indian Journal of Applied Basic Medical Sciences. 2012; 14: 98-103.

9. Shetty S, Nayak S, Kumar N, Abhinitha P. Hypoplastic anterior tibial artery associated with continuation of fibular (peroneal) artery as dorsalis pedis artery. A case report. Int $\mathrm{J}$ Morphol. 2013; 31(1):136-139.

10. Mitra NK, Habbal OA, El-Hag AH, Al-Hashmi NA. Bilateral absence of the arcuate artery on the dorsum of the foot. Sultan Qaboos Univ Med J. 2007; 7(2): 153-155.

11. Rajeshwari MS, Roshankumar BN, Vijayakumar. An anatomical study on dorsalis pedis artery. Int J Anat Res. 2013; 1(2): 8892 